\title{
Integrative analysis associated with cardiovascular disease and Omega-Probiotic intake
}

\author{
L. A. Torres-González ${ }^{1}$, J. P. Martínez-Solís ${ }^{1}$, F. J. Mendoza-Patiño ${ }^{1}$, A. Gamiño-Iriarte ${ }^{1}$ \\ and L. Reyes-Escogido ${ }^{2}$ \\ ${ }^{1}$ Universidad Iberoamericana León, Blvd. Jorge Vértiz Campero 1640, Cañada de Alfaro, CP 37238, León, Gto., México \\ and ${ }^{2}$ Universidad de Guanajuato, 20 de Enero 929, Col.Obregón, CP 37000, León, Gto., México adolfo.torres@leon.uia.mx
}

Cardiovascular diseases include factors such as lifestyle, diet and metabolic and gene expression processes. DNA microarray technique is used to quantify and compare gene expression on a large scale of genes. The gene expression through microarraýs technique is a current topic in the field of nutrigenomics for researching the complex gene networks and the relationship with Nutrition. We identified the genes associated with cardiovascular disease susceptible to modify their level of expression in a profile of microarray data by effect of the interaction with some bioactive components present in the polyunsaturated fatty acids like omega-3 and omega- 6 .

We reviewed the responsible genes of cardiovascular disease and their expression levels by microarray using international databases and we assessed the possible interaction role of polyunsaturated fatty acids omega 3 and omega 6 and the relationship with Lactobacillus gasseri probiotic in specific genes to evaluate the interaction patterns between them. We identified a gene network expression of cardiovascular disease (FADS1, FADS2, ALOX5, FLAP, LTA4H, GALNTL1, CEBPB, ADIPOQ, BMP2, CFD, FABP4, LIPE, LPL, PLIN1 PPAR $\gamma$, PPAR $\alpha$, CD36, APO A, APO B and APO E) and the possible role of the relationship with omega-3 and omega-6 intake. In addition, we have formulated the clustering of gene networks by applying the mathematical procedure Principal Components Analysis (PCA) to the gene expression data point by introducing an interaction between neighbouring points.

The identification and comparison of gene expression levels associated with cardiovascular disease will help to guide future research work focus on effective treatments for patients with this disease and even to prevent health problems like coronary disease. The integrative analysis based on gene networks offers a new conceptual framework that could be important to understand Nutrigenomics and pathologies. 